\title{
A REVIEW OF APPROVED COVID-19 VACCINES
}

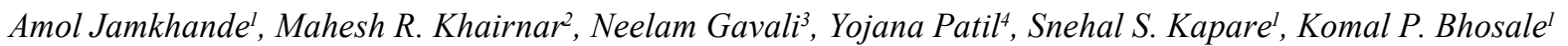 \\ ${ }^{1}$ Department of Public Health Dentistry, Bharati Vidyapeeth (Deemed to be University) Dental College \& Hospital, \\ Pune, Maharashtra, India \\ ${ }^{2}$ Public Health Dentistry, Faculty of Dental Sciences, Institute of Medical Sciences, Banaras Hindu University, \\ Varanasi, Uttar Pradesh, India \\ ${ }^{3}$ Department of Periodontics, Bharati Vidyapeeth (Deemed to be University) Dental College \& Hospital, \\ Pune, Maharashtra, India \\ ${ }^{4}$ Department of Public Health Dentistry, Tatyasaheb Kore Dental College \& Research Center, \\ New Pargaon, Warnanagar, Kolhapur, Maharashtra, India
}

\begin{abstract}
In the past one and half year elapsed since the identification of the SARS-CoV-2 virus and its genome, an extraordinary effort by the scientific community has led to the development of many vaccine projects. More than ten vaccine candidates throughout the world have been granted approval for emergency use. Existing data suggest that these vaccines have the potential to protect individuals and curb the spread of COVID-19 pandemic. However, long term side-effects and certain unresolved issues associated with vaccine use need to be assessed as the time passes. This study reviews the most recent data of 12 vaccines which have been approved for use and presents information on their doses, composition, mechanism of action, side effects, etc.
\end{abstract}

Key words: Covid-19 vaccines, immunization, $S A R S-C o V-2$

\section{INTRODUCTION}

In late December 2019, China reported cases of idiopathic pneumonia in the city of Wuhan. One month later, the causative agent was identified as severe acute respiratory syndrome coronavirus 2 (SARS-CoV-2). SARS-CoV-2 caused the epidemic of coronavirus disease 2019 (COVID-19) in different cities in China, which then spread globally and was later classified as a pandemic by the World Health Organization (WHO) $[1,2]$.

SARS-CoV-2 belongs to the genus Betacoronavirus in the family Coronaviridae. SARS$\mathrm{CoV}-2$ is an enveloped virus that contains a singlestranded positive-sense RNA genome of 29,903 nucleotides in length with 11 open reading frames (ORFs), which encode 27 viral proteins. ORF1a/b is 21,290 nucleotides length and encodes 16 nonstructural proteins (nsp1-nsp16). The last part of the genome is 8613 nucleotides that encodes four structural and six accessory proteins. The structural proteins are the spike ( $\mathrm{S}$, virus attachment and major antigenic protein), envelope (E), matrix (M), and nucleocapsid
(N) proteins while accessory proteins include ORF3a, ORF6, ORF7a, ORF7b, ORF8, and ORF10 [3, 4].

From a few thousand confirmed COVID-19 cases in January 2020, cases continue to grow globally, as of 17th June 2021, there have been 17,66,93,988 confirmed cases of COVID-19, including 38,30,304 deaths, reported to WHO.

The best way to prevent infection from COVID-19 is to avoid exposure to the virus. The virus spreads mainly from person-to-person through close contact. The basic preventive measures include simple public health measures such as vaccination that are to be followed to reduce the risk of infection with COVID-19. Vaccines greatly reduce the risk of infection by training the immune system to recognize and fight pathogens such as viruses or bacteria. The worldwide endeavor to create a safe and effective COVID-19 vaccine is bearing fruit. More than a dozen vaccines now have been authorized around the globe; many more remain in development.

A COVID-19 vaccine is a vaccine intended to provide acquired immunity against severe acute 
respiratory syndrome coronavirus 2 (SARSCoV2), the virus causing coronavirus disease 2019 (COVID-19).

\section{COMIRNATY (BNT162B2) (PFIZER)}

The Pfizer-BioNTech COVID-19 vaccine (INN: tozinameran), sold under the brand name Comirnaty, is an mRNA-based COVID-19 vaccine [5].

Medical use: The vaccine is given by intramuscular injection. It is composed of nucleoside-modified mRNA (modRNA) encoding a mutated form of the full-length spike protein of SARS-CoV-2, which is encapsulated in lipid nanoparticles. Vaccination requires two doses given three weeks apart $[6,7]$.

Composition: In addition to the mRNA molecule, the vaccine contains the following inactive ingredients (excipients): ALC-0315, ((4-hydroxybutyl) azanediyl) bis (hexane-6, 1-diyl) bis (2-hexyldecanoate); ALC-0159, 2-[(polyethylene glycol)-2000]-N, $\mathrm{N}$-ditetradecylacetamide; 1, 2-distearoyl-sn-glycero3-phosphocholine (DSPC); Cholesterol; Dibasic sodium phosphate dihydrate; Monobasic potassium phosphate; Potassium chloride; Sodium chloride; Sucrose; Water for injection.

Mechanism of action: Nucleoside-modified messenger RNA (modRNA) encoding the viral spike (S) glycoprotein of SARS-CoV-2; formulated in lipid particles, which enable delivery of RNA into host cells to allow expression of the SARS-CoV-2 S antigen and elicits an immune response to the $\mathrm{S}$ antigen, which protects against COVID-19.

Vaccine efficacy: The vaccine showed $95 \%$ efficacy at preventing Covid-19 illness [8].

Side effects: The side effect profile of the PfizerBioNTech COVID-19 vaccine is similar to that of other adult vaccines. During clinical trials, the side effects deemed very common are (in order of frequency): pain and swelling at the injection site, tiredness, headache, muscle aches, chills, joint pain, and fever. Fever is more common after the second dose [5].

\section{MODERNA COVID-19 VACCINE (mRNA-1273)}

The Moderna COVID-19 vaccine, codenamed mRNA-1273, is a COVID-19 vaccine developed by Moderna, the United States National Institute of Allergy and Infectious Diseases (NIAID) and the Biomedical Advanced Research and Development Authority (BARDA) [9].

Medical use: It is designed to be administered as two $0.5 \mathrm{~mL}$ doses given by intramuscular injection at an interval of four weeks apart [10].

Composition: Nucleoside-modified messenger RNA encoding the SARS-CoV-2 spike glycoprotein
(S) stabilized in its prefusion configuration; Lipids [SM-102, Polyethylene glycol (PEG) 2000-dimyristoyl glycerol (DMG), Cholesterol, and 1,2-distearoyl-snglycero-3-phosphocholine (DSPC); Tromethamine; Tromethamine hydrochloride; Acetic acid; Sodium acetate; Sucrose [11].

Mode of action: The Moderna COVID-19 Vaccine uses mRNA to provide a blueprint for your cells to build your body's defense against the virus. The nucleosidemodified mRNA in the Moderna COVID-19 Vaccine is formulated in lipid particles, which enable delivery of the nucleoside modified mRNA into host cells to allow expression of the SARSCoV2 Spike antigen. The vaccine elicits an immune response to the Spike antigen, which protects against COVID-19.

Vaccine efficacy: The mRNA-1273 vaccine showed 94.1\% efficacy at preventing Covid-19 illness [12].

Side effects: Side effects that have been reported with the Moderna COVID-19 Vaccine include [13]:

- Injection site reactions: pain, tenderness and swelling of the lymph nodes in the same arm of the injection, swelling (hardness), and redness.

- General side effects: fatigue, headache, muscle pain, joint pain, chills, nausea and vomiting, and fever.

\section{ASTRA ZENECA COVID-19 VACCINE (AZD1222); also known as Vaxzevria and Covishield}

The Oxford-AstraZeneca COVID-19 Vaccine, codenamed AZD1222, and sold under the brand names Covishield and Vaxzevria among others, is a viral vector vaccine for prevention of COVID-19. Developed by the Oxford University and Astra Zeneca, it is given by intramuscular injection, using as a vector the modified chimpanzee adenovirus ChAdOx1 [14].

Medical uses: The Oxford-AstraZeneca COVID-19 vaccine is used to provide protection against infection by the SARS-CoV-2 virus in order to prevent COVID-19 in adults aged 18 years and older. The medicine is administered by two $0.5 \mathrm{ml}$ doses injected intramuscularly into the deltoid muscle (upper arm) four to twelve weeks apart, with the WHO recommending the second is given 8 to 12 weeks after the first for optimum efficacy [15].

Composition: The Covishield Vaccine includes the following ingredients: ChAdOx1 $\mathrm{nCoV}-19$ Corona Virus Vaccine (Recombinant) $5 \times 10$ viral particles (*Recombinant, replication-deficient chimpanzee adenovirus vector encoding the SARS-CoV-2 Spike (S) glycoprotein. Produced in genetically modified human embryonic kidney (HEK) 293 cells); L-histidine; L-histidine hydrochloride monohydrate; Magnesium chloride hexahydrate; Polysorbate 80; 
Ethanol; Sucrose; Sodium chloride; Disodium edetate dihydrate (EDTA); Water for injection.

Mode of action: The Oxford-AstraZeneca COVID-19 vaccine is a replication-deficient simian adenovirus vector, containing the full-length. The adenovirus is called replication-deficient because some of its essential genes were deleted and replaced by a gene coding for the spike protein. Following vaccination, the adenovirus vector enters the cells and releases its genes, which are transported to the cell nucleus; thereafter the cell's machinery does the transcription into mRNA and the translation into proteins. The protein of interest is the spike protein, an external protein that enables the SARS-type coronavirus to enter cells through the enzymatic domain of ACE2. Producing it following vaccination will prompt the immune system to attack the coronavirus through antibodies and T-cells if it later infects the body.

Vaccine efficacy: An analysis published on 19 February 2021 showed an efficacy of $76.0 \%$ at preventing symptomatic COVID-19 beginning at 22 days following the first dose, increasing to $81.3 \%$ when the second dose is given 12 weeks or more after the first [16].

Side effects: The most common side effects in the clinical trials were usually mild or moderate and got better within a few days after vaccination. Vomiting, diarrhea, swelling, redness at the injection site and low levels of blood platelets occurred in less than 1 in 10 people. Enlarged lymph nodes, decreased appetite, dizziness, sleepiness, sweating, abdominal pain, itching and rash occurred in less than 1 in 100 people. In very rare cases (around 1 in 100,000 people) the vaccine can lead to blood clots in combination with low levels of blood platelets [17].

\section{SPUTNIK V (rAd26 and rAd5)}

Sputnik V is an adenovirus viral vector vaccine for COVID-19 developed by the Gamaleya Research Institute of Epidemiology and Microbiology in Russia. Also known as Gam-COVID-Vac is a combined vector vaccine, based on rAd type 26 (rAd26) and rAd type 5 (rAd5) - both of which carry the gene for SARS-CoV-2 full-length glycoprotein S (rAd26-S and rAd5-S) [18, 19, 20, 21].

Medical use: It is administered intramuscularly separately with a 21-day interval [20].

\section{Components:}

- Active ingredient: recombinant adenoviral particles of the 26 serotype containing the gene for the protein $\mathrm{S}$ of the SARS-CoV-2 virus, in an amount of $(1.0 \pm 0.5) \times 10^{11}$ particles / dose.
- Excipients: tris (hydroxylmethyl) aminomethane $1.21 \mathrm{mg}$, sodium chloride $-2.19 \mathrm{mg}$, sucrose - 25.0 $\mathrm{mg}$, magnesium chloride - $102.0 \mu \mathrm{g}$, EDTA sodium salt dihydrate - $19.0 \mu \mathrm{g}$, polysorbate $80-250 \mu \mathrm{g}$, ethanol $95 \%-2.5 \mu$, water for injection up to 0.5 $\mathrm{ml}$ [20].

Mode of action: Sputnik V uses a weakened virus to deliver small parts of a pathogen and stimulate an immune response. It is a vector vaccine based on adenovirus DNA, in which the SARS-CoV-2 coronavirus gene is integrated. Adenovirus is used as a "container" to deliver the coronavirus gene to cells and start synthesizing the new coronavirus>s envelope proteins, "introducing" the immune system to a potential enemy.

Vaccine efficacy: The vaccine efficacy is more than $91 \%$ according to the data released [20].

\section{Side effects:}

- Short-term general (short-term flu-like syndrome, characterized by chills, fever, arthralgia, myalgia, asthenia, general malaise, headache) and local (soreness at the injection site, hyperemia, swelling) reactions) may develop.

- Less commonly, nausea, dyspepsia, decreased appetite, and sometimes an increase in regional lymph nodes are noted.

- Some patients may develop allergic reactions, a short-term increase in the level of hepatic transaminases, creatinine and creatine phosphokinase in the blood serum [20].

\section{SPUTNIK LIGHT}

Sputnik Light is a single dose COVID-19 vaccine developed by the Gamaleya Research Institute of Epidemiology and Microbiology in Russia. It actually consists of the first dose of the Sputnik V vaccine, which is based on the $\operatorname{Ad} 26$ vector, and it can be stored at a normal refrigerator temperature of $2-8{ }^{\circ} \mathrm{C}(36-$ $\left.46^{\circ} \mathrm{F}\right)[22,23,24]$.

Efficacy: The single dose Sputnik Light vaccine demonstrated 79.4 per cent efficacy, according to analyzed data taken from 28 days after the injection was administered. An efficacy level of near 80 per cent is higher than that of many two-dose vaccines [25].

Immunogenicity: Sputnik Light can elicit the development of antigen specific IgG antibodies in $96.9 \%$ of individuals on the 28 th day after vaccination. The Sputnik Light vaccine elicits the development of virus neutralizing antibodies in $91.67 \%$ of individuals on the 28th day post immunization. Cellular immune response against the $\mathrm{S}$ Protein of SARS-CoV-2 develops in $100 \%$ of volunteers on the 10th day. The immunization of individuals with pre-existing immunity against SARS-CoV-2 with Sputnik Light can elicit the increase of the level of antigen specific 
IgG antibodies by more than $40 \mathrm{x}$ in $100 \%$ of subjects 10 days after immunization [26].

Side effects: No serious adverse events were registered after vaccination with Sputnik Light $[26,27]$.

\section{JANSSEN COVID-19 VACCINE (JNJ-78436735; Ad26.COV2.S)}

The Janssen or Johnson \& Johnson COVID-19 vaccine is a COVID-19 vaccine that was developed by Janssen Vaccines in Leiden, Netherlands, and its Belgian parent company Janssen Pharmaceuticals, subsidiary of American company [28].

Medical use: It is administered as a single dose [29].

Components: Recombinant, replicationincompetent adenovirus type 26 expressing the SARS-CoV-2 spike protein; Citric acid monohydrate; Trisodium citrate dehydrate; Ethanol;2-hydroxypropyl$\beta$-cyclodextrin (HBCD); Polysorbate-80; Sodium chloride [30]

Mode of action: A modified type of adenovirus is used that can enter the human cells but don't cause any illness or replicate. After injecting the vaccine, these adenoviruses latch onto proteins of human cells and enter it to release the adenovirus which eventually pushes its own DNA into the nucleus and mRNA containing gene for coronavirus spike protein is made and the spike proteins that are made are recognized by the immune system and antibodies against them are performed.

Vaccine efficacy: The J\&J one-dose vaccine was shown to be $66 \%$ protective against moderate to severe Covid infections overall from 28 days after injection, though there was variability based on geographic locations. The vaccine was $72 \%$ protective in the United States, $66 \%$ protective in South America, and $57 \%$ protective in South Africa. But the vaccine was shown to be $85 \%$ protective against severe disease, with no differences across the eight countries or three regions in the study, nor across age groups among trial participants [30].

Side effects: headache; fever; fatigue; muscle aches; nausea; pain, irritation, redness, and swelling at the site of the injection; Blood clots involving blood vessels in the brain, abdomen, and legs along with low levels of platelets, has occurred in some people who have received the Janssen COVID-19 Vaccine. In people who developed these blood clots and low levels of platelets, symptoms began approximately one to two-weeks following vaccination [31, 32].

\section{COVAXIN (BBV152)}

Covaxin (codenamed as BBV152) is an inactivated virus based COVID-19 vaccine developed by Bharat
Biotech in collaboration with the Indian Council of Medical Research [33].

Medical use: It is given as an injection into the deltoid muscle of the upper arm. The BHARAT BIOTECH COVID-19 VACCINE (COVAXIN) vaccination series is 2 doses given 4-6 weeks apart [34].

Components: $6 \mu \mathrm{g}$ of whole-virion inactivated SARSCoV-2 antigen (Strain: NIV-2020-770); Aluminum hydroxide gel $(250 \mu \mathrm{g})$; TLR $7 / 8$ agonist (imidazoquinolinone) $15 \mu \mathrm{g}$; 2-phenoxyethanol 2.5 $\mathrm{mg}$; Phosphate buffer saline up to $0.5 \mathrm{ml}$ [34].

Mode of action: COVAXIN induced binding and neutralizing antibody responses and with the inclusion of the Algel-IMDG adjuvant, this is the first inactivated SARS-CoV-2 vaccine that has been reported to induce a Th1-biased response [35].

Vaccine efficacy: Phase 3 results of the COVAXIN, developed by Indian Council of Medical Research (ICMR) in partnership with Bharat Biotech International Limited (BBIL), and has shown an interim vaccine efficacy of $81 \%$ in preventing Covid- 19 [36]. COVAXIN is found to protect individuals against the Beta (B.1.351) and Delta (B.1.617.2) variants, more commonly referred to as the South African and Indian variants of the Covid-19 virus [37].

Side effects: Injection site pain, swelling, redness, itching, stiffness in the upper arm, weakness in injection arm, body ache, headache, fever, malaise, weakness, rashes, nausea, vomiting were observed after the vaccine was administered. It may cause a severe allergic reaction of which signs are: difficulty in breathing, swelling of the face and throat, a fast heartbeat, rash all over your body, dizziness and weakness [38].

\section{CORONA VAC}

CoronaVac, also known as the Sinovac COVID-19 vaccine, is an inactivated virus COVID-19 vaccine developed by the Chinese company Sinovac Biotech [39]. CoronaVac does not need to be frozen and both the final product and the raw material for formulating CoronaVac can be transported refrigerated at $2-8^{\circ} \mathrm{C}$ $\left(36-46^{\circ} \mathrm{F}\right)$, temperatures at which flu vaccines are kept.

Medical use: Two doses should be administered by intramuscular injection in the deltoid region of the upper arm. Vaccine is administered on a 14-28-day schedule [40].

Components: Inactivated SARS-CoV-2 Virus9CZ02 strain); Aluminum hydroxide; Disodium hydrogen phosphate dodecahydrate; Sodium dihydrogen phosphate monohydrate; Sodium chloride [41].

Mode of action: Part of the coronavirus' genetic code is injected into the body, triggering the body to 
begin making viral proteins, but not the whole virus, which is enough to train the immune system to attack and hence, immunity is developed.

Vaccine efficacy: A real-world study of millions of people who received Corona Vac, as published by the WHO found the vaccine $67 \%$ effective against symptoms, reduced hospitalizations by $85 \%$, intensive care visits by $89 \%$, and deaths by $80 \%$ [42].

Side effects: Blood Pressure Increase; Headache; Vaccination site pain; Dizziness; Rash [43].

\section{SINOPHARM BBIBP-CorV COVID-19}

Sinopharm BBIBP-CorV, also known as the Sinopharm COVID-19 vaccine, is one of two inactivated virus COVID-19 vaccines developed by Sinopharm $>$ s Beijing Institute of Biological Products, China [44].

Medical use: The WHO recommends the Sinopharm vaccine for people aged 18 years and older, with a gap of 3-4 weeks between the two doses [45].

Components: Sinopharm's SARS-CoV-2 strain (WIV04 strain and Gen Bank number MN996528) was isolated from a patient in the Jinyintan Hospital, Wuhan, China. The virus was cultivated in a qualified Vero cell line for propagation, and the supernatant of the infected cells was inactivated with $\beta$-propiolactone $\left(1: 4000 \mathrm{vol} / \mathrm{vol}\right.$ at 2 to $\left.8^{\circ} \mathrm{C}\right)$ for 48 hours. Following clarification of cell debris and ultrafiltration, the second $\beta$-propiolactone inactivation was performed in the same conditions as the first inactivation. The vaccine was adsorbed to $0.5 \mathrm{mg}$ alum and packed into prefilled syringes in $0.5 \mathrm{~mL}$ sterile phosphate-buffered saline without preservative, says the WHO [45].

Mode of action: Inactivated vaccines use the killed version of the germ that causes a disease and works by teaching the immune system to make antibodies against the SARS-CoV-2 beta coronavirus.

Vaccine efficacy: In May 2021, peer-reviewed results published in JAMA of Phase III trials in United Arab Emirates and Bahrain showed BBIBP-CorV $78.1 \%$ effective against symptomatic cases and $100 \%$ against severe cases [46].

\section{Side effects:}

- The most common side effects were: headaches; fatigue; injection site reactions

- The WHO identified two serious adverse events that were possibly linked to the vaccine: serious nausea and a rare neurological disorder known as acute disseminated encephalomyelitis. There was also one diagnosis of thrombus (blood clot) in the vaccine group [47].

\section{CONVIDICEA \\ (PakVac, Ad5-nCoV)}

Convidicea - Ad5-nCoV, trade-named Convidicea, is a single-dose viral vector vaccine for COVID-19 developed by CanSino Biologics (Tianjin, China) [48]. It conducted its Phase III trials in Argentina, Chile, Mexico, Pakistan, Russia, and Saudi Arabia with 40,000 participants. Convidecia is authorized for use in China, Mexico, Pakistan, Hungary, and Chile. Not authorized by the WHO and European Commission.

Medical use: It is administered as a single dose [49].

Components: Contained replication-defective Ad5 vectors expressing the full-length spike gene based on Wuhan-Hu-1 (GenBank accession number YP_009724390) [49].

Mode of action: The new Ad5 vectored COVID-19 vaccine evaluated in the phase 1 trial is the first to be tested in humans. It uses a weakened common cold virus (adenovirus, which infects human cells readily but is incapable of causing disease) to deliver genetic material that codes for the SARS-CoV-2 spike protein to the cells. These cells then produce the spike protein and travel to the lymph nodes, where the immune system creates antibodies that will recognize that spike protein and fight off the coronavirus.

Vaccine efficacy: In February 2021, data released from an interim analysis of Phase III trials with 30,000 participants and 101 COVID cases showed that globally, the vaccine had an efficacy of $65.7 \%$ at preventing moderate cases of COVID-19 and $90.98 \%$ efficacy at preventing severe cases [50].

\section{Side effects:}

- Injection site adverse reactions included: pain, induration, redness, swelling, itching

- Systemic adverse reactions included: fever, headache, fatigue, vomiting, diarrhea, muscle pain, cough, nausea, etc. [49].

\section{EpiVacCorona}

EpiVacCorona is a COVID-19 preventive vaccine developed by the Vector State Research Center of Virology and Biotechnology in Russia. EpiVacCorona is an antigens-based vaccine [51].

Mode of action: The vaccine relies on chemically synthesized peptide antigens of SARS-CoV-2 proteins, conjugated to a carrier protein and adsorbed on an aluminum-containing adjuvant (aluminum hydroxide) [51]. the vaccine does not contain the live virus and forms immunity due to artificially synthesized peptides. EpiVacCorona consists of three synthetic fragments of spike, attached to a carrier protein, which itself is composed of synthetic fragments of the virus nucleocapsid protein, known as N. One peptide is 
designed to create antibodies to the spike's receptorbinding domain, the part that hooks onto a human cell protein. The other spike peptides are meant to elicit antibodies that prevent the virus from getting into the cell. The $\mathrm{N}$ peptides may generate still other protective responses. VECTOR officials say the vaccine ultimately provides "three lines of defense" [52].

Vaccine efficacy: The efficacy is shown to be $100 \%$ according to the study published [53].

\section{RBD-Dimer/ZIFIVAX}

ZF2001, trade-named ZIFIVAX, is an adjuvanted protein subunit COVID-19 vaccine developed by Anhui Zhifei Longcom in collaboration with the Institute of Microbiology at the Chinese Academy of Sciences. ZifiVax ZF2001 is a protein subunit vaccine using a dimeric form of the receptor-binding domain (RBD) as the antigen, a harmless piece of the SARSCov-2 virus. ZF2001 was first approved for use in Uzbekistan and later China [54].

Medical use: It's a three-dose shot that is spaced out with one month each between shots [55].

\section{LIMITATIONS OF CURRENT VACCINES}

Though the vaccines have shown promising results, there are some area which remain unanswered. With such a short duration involved in their development and the novelty of the technologies used, these vaccines will be used with some unanswered issues that only passage of time will allow to elucidate. Issues such as how much protection do these vaccines provide against different variants of Novel Corona Virus? What is the duration of immune response generated? Is there any need for a booster dose after taking recommended doses of a particular vaccine? Can these vaccines be administered to younger children and pregnant women? How much effective are these vaccines against asymptomatic cases i.e. can these vaccines stop transmission of infection from asymptomatic cases? Need to be answered through long term research.

\section{CONCLUSION}

Higher efficacy rates were seen with approved vaccines (mRNA based, inactivated and viral vectors vaccines). Pfizer's Comirnaty is the first vaccine to get approval for 12-15-year age group. So far, high reactogenicity was seen with mRNA based vaccines and low with in inactivated vaccines. Those who are administered with viral vectored vaccines and mRNA vaccines need to be observed for thrombotic events and myocarditis respectively.

\section{Conflict of interest}

None.

\section{REFERENCES}

1. Zhou P., Yang XL., Wang XG., Hu B., Zhang L., Zhang $W$., et al. A pneumonia outbreak associated with a new coronavirus of probable bat origin. Nature. 2020; 579(7798):270-273. DOI: 10.1038/s41586-020-2012-7

2. Wu F., Zhao S., Yu B., Chen Y-M., Wang W., Song $Z-G$., et al. A new coronavirus associated with human respiratory disease in China. Nature. 2020; 579(7798):265-269. DOI: 10.1038/s41586-020-2008-3

3. Chan JF-W., Kok K-H., Zhu Z, Chu H., To KK-W., Yuan S., et al. Genomic characterization of the 2019 novel human-pathogenic coronavirus isolated from a patient with atypical pneumonia after visiting Wuhan. Emerging Microbes \&amp; Infections. 2020; 9(1):221236. doi: $10.1080 / 22221751.2020 .1719902$.

4. Helmy YA., Fawzy M., Elaswad A., Sobieh A., Kenney SP., Shehata AA. The COVID-19 Pandemic: A Comprehensive Review of Taxonomy, Genetics, Epidemiology, Diagnosis, Treatment, and Control. $J$ Clin Med. 2020;9(4):1225. Published 2020 Apr 24. doi: $10.3390 / \mathrm{jcm} 9041225$

5. Dimitrova E.K. Comirnaty [Internet]. European Medicines Agency. BioNTech Manufacturing GmbH; 2021 Available from: https://www.ema.europa.eu/ en/medicines/human/EPAR/comirnaty. (Accessed: 10.07.2021)

6. Walsh EE., Frenck RW., Falsey AR., Kitchin N., Absalon $J$., Gurtman A., et al. Safety and Immunogenicity of Two RNA-Based Covid-19 Vaccine Candidates. N Engl J Med 2020; 383:2439-2450. DOI: 10.1056/ NEJMoa2027906

7. Information for Healthcare Professionals on Pfizer/ BioNTech COVID-19 vaccine [Internet]. GOV.UK. Available from: https://www.gov.uk/government/ publications/regulatory-approval-of-pfizer-biontechvaccine-for-covid-19/information-for-healthcareprofessionals-on-pfizerbiontech-covid-19-vaccine. (Accessed: 10.07.2021)

8. Polack FP, Thomas SJ, Kitchin N, Absalon J, Gurtman $A$, Lockhart $S$, et al. Safety and Efficacy of the BNT162b2 mRNA Covid-19 Vaccine. N Engl J Med 2020; 383(27):2603-15. doi: 10.1056/NEJMoa2034577.

9. DailyMed - MODERNA COVID-19 VACCINEcx-024414 injection, suspension [Internet]. U.S. National Library of Medicine. National Institutes of Health. Available from: https://dailymed.nlm.nih.gov/ dailymed/drugInfo.cfm?setid=e0651c7a-2fe2-459da766-0d59e919f058. (Accessed: 10.07.2021)

10. Czarska-Thorley D. COVID-19 Vaccine Moderna [Internet]. European Medicines Agency. 2021. Available from: https://www.ema.europa.eu/en/medicines/ human/EPAR/covid-19-vaccine-moderna. (Accessed: 10.07.2021)

11. Moderna COVID-19 Vaccine Overview and Safety [Internet]. Centers for Disease Control and Prevention. Centers for Disease Control and Prevention; 2021. 
Available from: https://www.cdc.gov/coronavirus/2019ncov/vaccines/different-vaccines/Moderna.html. (Accessed: 10.07.2021)

12. Baden LR., El Sahly HM., Essink B., Kotloff K., Frey $S$., Novak R., et al. Efficacy and Safety of the mRNA1273 SARS-CoV-2 Vaccine. New Eng J Med 2021; 384(5):403-16. doi/10.1056/NEJMoa2035389.

13. Moderna COVID-19 Vaccine EUA Fact Sheet for Recipients and ... [Internet]. Moderna COVID-19 Vaccine EUA Fact Sheet for Recipients. 2021 Available from: https://www.fda.gov/media/144638/download . (Accessed: 10.07.2021)

14. Clinical trials [Internet]. Clinical Trials Register. 2021. Available from: https://www.clinicaltrialsregister. eu/ctr-search/trial/2020-001228-32/GB. (Accessed: 10.07.2021)

15. Smith P. [Internet]. WHO-2019-nCoV-vaccines-SAGE recommendation-AZD1222-2021.2-eng.pdf. 2021. Available from: https://apps.who.int/iris/bitstream/ handle/10665/340920/WHO-2019-nCoV-vaccinesSAGE_recommendation-AZD1222-2021.2-eng.pdf. (Accessed: 10.07.2021)

16. Voysey M., Weckx LY., Madhi SA., Clemens SA., Aley PK., Folegatti PM., et al. [Internet]. Single-dose administration and the influence of the timing of the booster dose on immunogenicity and efficacy of ChAdOx1 nCoV-19 (AZD1222) vaccine: a pooled analysis of four randomised trials. Lancet. 2021; 397(10277):881-891. doi: 10.1016/S0140-6736(21)004323.

17. Francisco EM.: AstraZeneca's COVID-19 vaccine: benefits and risks in context [Internet]. European Medicines Agency. 2021. Available from: https:// www.ema.europa.eu/en/news/astrazenecas-covid-19vaccine-benefits-risks-context. (Accessed: 10.07.2021)

18. Jon Cohen: Russia's approval of a COVID-19 vaccine is less than meets the press release [Internet]. Science. 2020. Available from: https://www.sciencemag.org/ news/2020/08/russia-s-approval-covid-19-vaccine-lessmeets-press-release. (Accessed: 10.07.2021)

19. Callaway E.: Russia's fast-track coronavirus vaccine draws outrage over safety [Internet]. Nature News. Nature Publishing Group; 2020. Available from: https:/www.nature.com/articles/d41586-020-02386-2. (Accessed: 10.07.2021)

20. Gam-COVID-Wack, Satellite V [Internet]. Combined vector vaccine for the prevention of coronavirus infection caused by the SARS-CoV-2 virus (GamCOVID-Vac). Available from: https://medum.ru/ sputnik-v. (Accessed: 10.07.2021)

21. Sputnik V Vaccine [Internet]. Welcome to Precision Vaccinations. Available from: https://www. precisionvaccinations.com/vaccines/sputnik-v-vaccine. (Accessed: 10.07.2021)

22. Sputnik V. General Information [Internet]. Available from: https://sputnikvaccine.com/about-vaccine/. (Accessed: 10.07.2021)

23. An Open Study on the Safety, Tolerability, and Immunogenicity of "Sputnik Light" Vaccine - Full Text View [Internet]. Full Text View - ClinicalTrials. gov. 2021. Available from: https://clinicaltrials.gov/ct2/ show/NCT04713488. (Accessed: 10.07.2021)

24. Study to Evaluate Efficacy, Immunogenicity and Safety of the Sputnik-Light - Full Text View [Internet]. Study to Evaluate Efficacy, Immunogenicity and Safety of the Sputnik-Light - Full Text View - ClinicalTrials. gov. Available from: https://clinicaltrials.gov/ct2/show/ NCT04741061. (Accessed: 10.07.2021)

25. Mounting evidence suggests Sputnik COVID vaccine is safe and effective [Internet]. mint. Nature. 2021. Available from: nature.com/articles/d41586-021-018132. (Accessed: 10.07.2021)

26. An Open Study on the Safety, Tolerability, and Immunogenicity of "Sputnik Light" Vaccine [Internet]. Welcome to Precision Vaccinations. Available from: https://www.precisionvaccinations.com/clinical-trials/ open-study-safety-tolerability-and-immunogenicitysputnik-light-vaccine. (Accessed: 11.07.2021)

27. Desk FPJW. What is Sputnik Light? All you need to know about Russia's single shot COVID-19 vaccine [Internet]. Free Press Journal. Available from: https:// www.freepressjournal.in/india/what-is-sputnik-lightall-you-need-to-know-about-russias-single-shot-covid19-vaccine. (Accessed: 11.07.2021)

28. Janssen COVID-19 Vaccine (Johnson \& Johnson) [Internet]. 2021. Available from: https://www.cdc.gov/ vaccines/covid-19/info-by-product/janssen/index.html. (Accessed: 11.07.2021)

29. Fact sheet for healthcare providers administering vaccine (vaccination providers). Emergency use authorization (EUA) of The Janssen COVID-19 Vaccine to prevent Coronavirus Disease 2019 (COVID-19). 2021. Available from: https:/www.fda.gov/media/146304/download. (Accessed: 11.07.2021)

30. Interim recommendations for the use of the Janssen Ad26. COV2.S (COVID-19) vaccine [Internet]. World Health Organization. World Health Organization. Available from: https://www.who.int/publications/i/item/WHO2019-nCoV-vaccines-SAGE-recommendation-Ad26. COV2.S-2021.1. (Accessed: 11.07.2021)

31. Janssen COVID-19 Vaccine. Fact Sheet for Recipients and Caregivers. Emergency use authorization (EUA) of the Janssen COVID-19 Vaccine to prevent coronavirus disease 2019 (COVID-19) in individuals 18 years of age and older. [Internet]. .Available from: https://www.fda. gov/media/146305/download. (Accessed: 11.07.2021)

32. CDC Recommends Use of Johnson \& Johnson's Janssen COVID-19 Vaccine Resume [Internet]. 2021. Available from: https://www.cdc.gov/coronavirus/2019-ncov/ vaccines/safety/JJUpdate.html\#: :text=syndrome $\% 20$ (TTS).-,TTS $\% 20$ is $\% 20 a \% 20$ serious $\% 20$ condition $\% 20$ that $\% 20$ involves $\% 20$ blood $\% 20$ clots $\% 20$ with,a $\% 20$ median\%20of\%2037\%20years. (Accessed: 11.07.2021)

33. Bharat Biotech-Vaccines \&amp; Bio-Therapeutics Manufacturer in India. Available from: https:// www.bharatbiotech.com/covaxin.html. (Accessed: 11.07.2021)

34. COVAXIN Factsheet-V2_cc.cdr. [Internet]. 2021. Available from: https://www.bharatbiotech.com/ 
images/covaxin/covaxin-factsheet.pdf.

(Accessed: 11.07.2021)

35. Ganneru B., Jogdand H., Daram VK., Das D., Molugu NR., Prasad SD., et al. Th1 skewed immune response of whole virion inactivated SARS CoV 2 vaccine and its safety evaluation. iScience. 2021; 24(4):102298. doi: 10.1016/j.isci.2021.102298.

36. Thiagarajan $K$. What do we know about India's Covaxin vaccine? BMJ. 2021;373:n997 doi: 10.1136/bmj.n997.

37. Sapkal G., Yadav P., Ella R., Abraham P., Patil D., Gupta $N$., et al. Neutralization of B.1.1.28 P2 variant with sera of natural SARS-CoV-2 infection and recipients of BBV152 vaccine. Journal of Travel Medicine. 2021. 1-3. doi: $10.1093 /$ jtm/taab077.

38. Fact Sheet for Vaccine Recipients and Caregivers Restricted Use of COVAXIN ${ }^{\mathrm{TM}}$ Under Clinical Trial Mode. The Bharat Biotech Covid-19 Vaccine (COVAXIN $^{\mathrm{TM}}$ ) to Prevent Coronavirus Disease 2019 (COVID-19). [Internet]. 2021. Available from: https:// cdsco.gov.in/opencms/export/sites/CDSCO_WEB/en/ biotechver.pdf. (Accessed: 12.07.2021)

39. Posted by Fancy Comma LLC. How Does China's CoronaVac Vaccine for COVID-19 Work? [Internet]. Fancy Comma, LLC. 2021. Available from: https:// fancycomma.com/2020/07/22/coronavac-inactivatedcovid19-vaccine/ (Accessed: 12.07.2021)

40. SINOVAC BIOTECH LTD. COVID-19 Vaccine (Vero cell), inactivated. [Internet]. 2021. Available from: https:/cdn.who.int/media/docs/default-source/ immunization/sage/2021/april/4_sage29apr2021 sinovac.pdf?sfvrsn=2d82605d 5(Accessed: 12.07 .2021$)$

41. Qazi A. 20210421-Guidelines-for-Sinovac-6301 [Internet]. 2021. Available from: http://www.hsa.edu. pk/wp-content/uploads/20210421-Guidelines-forSinovac-6301.pdf. (Accessed: 12.07.2021)

42. World Health Organization. Evidence Assessment. Sinovac/CoronaVac COVID-19 vaccine. [Internet]. 2021 Available from: https://cdn.who.int/media/ docs/default-source/immunization/sage/2021/ april/5_sage29apr2021_critical-evidence_sinovac. pdf?sfvrsn=2488098d_5. (Accessed: 12.07.2021)

43. COVID-19 Vaccine (Vero cell), Inactivated (Brief Edition). [Internet]. 2021. Available from: https://www. covidvaccine.gov.hk/pdf/CoronaVac ENG PI brief. pdf. (Accessed: 12.07.2021)

44. COVID-19Vaccine(VeroCell), Inactivated(Sinopharm). [Internet]. 2021. Available from: https://www.who. int/docs/default-source/coronaviruse/v.3_21195 sinopharm-vaccine-explainer-24.pdf?sfvrsn=e7507eb4 19\&download=true. (Accessed: 12.07.2021)

45. The Sinopharm COVID-19 vaccine: What you need to know [Internet]. World Health Organization. World Health Organization. Available from: https://www.who. $\mathrm{int} /$ news-room/feature-stories/detail/the-sinopharmcovid-19-vaccine-what-you-need-to-know. (Accessed: 12.07.2021)

46. Evidence Assessment: Sinopharm/BBIBP COVID-19 vaccine. [Internet]. 2021. Available from: https://cdn. who.int/media/docs/default-source/immunization/ sage/2021/april/2_sage29apr2021_critical-evidence sinopharm.pdf. (Accessed: 12.07.2021)

47. Saeed BQ., Al-Shahrabi R., Alhaj SS., Alkokhardi ZM., Adrees $A O$. Side Effects and Perceptions Following Sinopharm COVID-19 Vaccination. BMJ Yale. $2021 \mathrm{Jul}$ 1. (Preprint) [Internet]. Available from: https://www. medrxiv.org/content/10.1101/2021.06.28.21258847v1. (Accessed: 12.07.2021)

48. Convidicea Vaccine (Ad5-nCoV) Description [Internet]. 2021 Jun 30. Available from: https://www. precisionvaccinations.com/vaccines/convidiceavaccine. (Accessed: 12.07.2021)

49. Zhu F-C., Guan X-H., Li Y-H., Huang J-Y., Jiang T., Hou $L-H$., et al. Immunogenicity and safety of a recombinant adenovirus type-5-vectored COVID-19 vaccine in healthy adults aged 18 years or older: a randomised, double-blind, placebo-controlled, phase 2 trial. The Lancet. 2020;396(10249):479-88. doi: 10.1016/S01406736(20)31605-6.

50. CanSino COVID-19 vaccine. Efficacy and effectiveness of the vaccine. [Internet]. 2021 Available from: https:// covid-19pharmacovigilance.paho.org/vacuna-decansino. (Accessed: 13.07.2021)

51. EpiVacCorona Vaccine [Internet]. Welcome to Precision Vaccinations. Available from: https://www. precisionvaccinations.com/vaccines/epivaccoronavaccine. (Accessed: 13.07.2021)

52. Dobrovidova O. Russia's COVID-19 defense may depend on mystery vaccine from former bioweapons lab-but does it work? [Internet]. Science. 2021. [cited $2021 \mathrm{Jul}$ 13]. Available from: https://www.sciencemag. org/news/2021/04/russia-s-covid-19-defense-maydepend-mystery-vaccine-former-bioweapons-lab-doesit-work. (Accessed: 13.07.2021)

53. International LDS. Watchdog: Russia’s EpiVacCorona Vaccine Has '100 Percent Immunological Efficacy' [Internet]. Sputnik International. Sputnik Internationalhttps://cdn2.img.sputniknews.com/i/ logo.png; 2021. Available from: https://sputniknews. com/russia/202101191081813036-efficacy-of-russiasepivaccorona-vaccine-is-100-percent-watchdog-says/. (Accessed: 13.07.2021)

54. Zifivax (ZF2001) COVID-19 Vaccine [Internet]. 2021. Available from: https://www.precisionvaccinations. com/vaccines/zifivax-zf2001-covid-19-vaccine. (Accessed: 14.07.2021)

55. Yang S., Li Y., Dai L., Wang J., He P., Li C., et al. Safety and immunogenicity of a recombinant tandem-repeat dimeric RBD-based protein subunit vaccine (ZF2001) against COVID-19 in adults: two randomised, doubleblind, placebo-controlled, phase 1 and 2 trials. Lancet Infect Dis. 2021:S1473-3099(21)00127-4. doi: 10.1016/ S1473-3099(21)00127-4.

Received: 28.07.2021

Accepted: 19.08.2021 